\title{
La incidencia del principio de participación ambiental en la teoría del acto administrativo*
}

\author{
Incidence of the Environmental Participation Principle in the Administrative Act Theory
}

Diana Carolina Sánchez-Zapata ${ }^{\text {a }}$

DOI: https://doi.org/10.11144/Javeriana.vj70.ippa

Universidad de Antioquia, Colombia

diana.sanchez@udea.edu.co

ORCID: https://orcid.org/0000-0002-4992-8833

Recibido: 01 Septiembre 2020

Hernán Dario Vergara-Mesa

Aceptado: 24 Febrero 2021

Universidad de Antioquia, Colombia

Publicado: 22 Octubre 2021

ORCID: https://orcid.org/0000-0003-2288-2182

\section{Resumen:}

El artículo hace un análisis de la transformación de las decisiones unilaterales de la administración, a partir de la repercusión del principio de participación en el proceso de configuración de las decisiones administrativas, con el fin de aportar en la comprensión de una teoría del acto administrativo adaptable al ordenamiento jurídico colombiano. Se acude metodológicamente a la propuesta de revisión dogmática del derecho administrativo, y a los aportes de la parte especial del derecho administrativo para una reconstrucción de la teoría general. Se propone, así, el estudio del procedimiento administrativo especial para el otorgamiento de las licencias ambientales en Colombia como un "sector de referencia" que permite, conforme a los hallazgos obtenidos, el análisis y revisión de los elementos del acto administrativo y de las consecuencias dogmáticas con respecto a su validez, más allá del vicio por expedición irregular por afectación de su elemento formal, y abre la posibilidad de plantear la configuración de otros vicios relacionados con los elementos competencial, objetivo o finalístico, cuando los actos se expidan sin satisfacer los estándares de participación y justicia ambiental.

Palabras clave: unilateralidad, teoría del acto administrativo, principio de participación, validez de los actos administrativos, licencia ambiental.

\section{Abstract:}

The article analyzes the transformation of administration unilateral decisions, based on the incidence of participation principle in the formation process of administrative decisions, in order to contribute to the understanding of an adaptable administrative act theory in the colombian legal system. Methodological recourse, is based on the dogmatic revision of Administrative Law, and the contributions of the special part of Administrative Law as a way for the reconstruction to general theory. Thus, the study of the special administrative procedure for the granting of environmental licenses in Colombia is proposed as a 'reference sector', that allows according to the findings, the analysis of the administrative act elements and the dogmatic consequences regarding its validity, beyond the vice for irregular issuance due to affectation of its formal element. It generates the possibility of proposing the configuration of other vices related to the competency, objective or finalistic elements, when the administrative acts are issued without the standards of participation from environmental justice.

Keywords: unilateralism, administrative act theory, participation principle, validity of administrative acts, environmental license.

\section{Introducción}

La obra de Schmidt-Assmann ${ }^{1}$ ofrece una invitación a repensar las categorías empleadas por la dogmática jurídico-administrativa y a considerar una revisión crítica de los conceptos centrales del derecho administrativo (DA), a partir del análisis de las regulaciones específicas y de los componentes propios del estudio de la parte especial.

Notas de autor

\footnotetext{
a Autora de correspondencia. Correo electrónico: diana.sanchez@udea.edu.co
} 
Se propone analizar algunos de los aspectos configuradores de la teoría del acto administrativo, especialmente sus elementos estructurales, estudio ligado a los aspectos que conciernen a su validez, y al de los atributos que permiten identificar y diferenciar a los actos administrativos de otros actos jurídicos, entre ellos, particularmente, la unilateralidad.

El punto de partida de este análisis está relacionado con las consecuencias que se derivan para la Administración pública del paradigma de Estado constitucional, social y democrático de derecho que con mayores o menores grados ha sido acogido por la mayoría de los países del mundo, entre ellos Colombia, y de sus características que presuponen una tendencia a la superación de los rasgos autoritarios del Estado en diversos contextos, en los que se pueden advertir cambios importantes en las formas de relacionamiento con los ciudadanos, especialmente tratándose de la manera como adopta sus decisiones y del tipo de relaciones jurídico administrativas que configura.

Así, si bien los actos administrativos son identificables por los conocidos atributos de obligatoriedad, ejecutoriedad y presunción de legalidad, no necesariamente llevan implicada la misma estructura de unilateralidad reconocida tradicionalmente, pues algunos de ellos involucran una intensa participación de los administrados, cuya omisión podría cuestionar su validez ${ }^{2}$.

Uno de estos ámbitos lo ofrece precisamente el derecho ambiental, y concretamente los procedimientos para el otorgamiento de las licencias ambientales. Desde la perspectiva de Schmidt-Assmann, el medio ambiente cobra cada vez más importancia como tarea administrativa, y por eso le atribuye a este sector de referencia una particular relevancia que se deriva del hecho de ser un ámbito "constitucionalmente incardinado dentro de los fines del Estado" ${ }^{3}$. La garantía y protección del medio ambiente y de los recursos naturales ${ }^{4}$ se muestra como una labor principal de la que dependen mayores ámbitos de actuación de la Administración pública, constituye una preocupación transversal y permanente de toda acción administrativa, como la policía administrativa, el servicio público, la intervención económica o la regulación.

No obstante las facetas y manifestaciones de la actividad administrativa en relación con el medio ambiente, su análisis amerita una consideración y estudio específico desde el punto de vista del acto administrativo, como quiera que el ordenamiento jurídico tiene previstos procedimientos especiales de gran relevancia para las políticas de desarrollo actuales en el país, como son los dispuestos para el otorgamiento de licencias ambientales ${ }^{5}$. Este artículo tiene como objetivo profundizar en dicho ámbito particular de decisión administrativa con referencia especial a la revisión de sus elementos. Se acude metodológicamente a la perspectiva de investigación jurídica de tipo dogmática, a partir del reconocimiento de presupuestos y postulados propios del derecho positivo vigente para la comprensión e interpretación del carácter unilateral de los actos administrativos. Se parte de la definición de la investigación dogmática propuesta por Courtis en virtud de la cual "la dogmática se propone estudiar el ordenamiento jurídico para conocerlo, transmitir ese conocimiento, operarlo, optimizarlo, mejorarlo"6.

De acuerdo con esta conceptualización, se reconoce que la dogmática permite enfrentar problemas presentes en el campo jurídico relacionados con la indeterminación lingüística; problemas lógicos como el de la inconsistencia, el carácter incompleto y la redundancia de las normas; los problemas de determinación de valores y fines simultáneamente consagrados en un ordenamiento jurídico, así como la resolución de problemas derivados de la estructura jerárquica y escalonada del orden jurídico, en la búsqueda por la compatibilidad de disposiciones y la identificación de los fundamentos normativos aplicables a un caso concreto, aspectos que tienen que ver con las formas de evolución y desarrollo del derecho en las sociedades contemporáneas que se complejizan por fenómenos como la constitucionalización del derecho, la relevancia que adquieren otras fuentes jurídicas — más allá de la ley y de los reglamentos-como la jurisprudencia, así como la importancia que adquiere el derecho internacional frente a los compromisos internacionalmente adquiridos por los Estados. 
Estas funciones que cumple la dogmática resultan pertinentes para estudiar el proceso de evolución del derecho administrativo y es compatible con la propuesta sistematizadora e integradora que plantea SchmidtAssmann, en virtud de la cual es posible acudir a sectores de la parte especial del derecho administrativo para, por medio de un proceso inductivo-deductivo, reconocer desde la heterogeneidad y especialización de los múltiples escenarios en que debe actuar la Administración pública, aquellos ámbitos e institutos básicos de la teoría general que requieren actualizarse o replantearse.

Para el análisis que propone este artículo se acude al estudio del procedimiento especial para la expedición de las licencias ambientales, un sector de referencia para la toma de decisiones administrativas en el que es preciso identificar transformaciones en la relación entre la sociedad y el Estado, derivados de la función dogmática que cumple el principio de participación. Estos cambios, cabe reconocer, han sido estudiados a través de la faceta propia que cumple la participación frente a sujetos de especial protección como las comunidades étnicas a través del derecho fundamental a la consulta previa que exige el consentimiento previo, libre, expreso e informado, así como la incidencia real en los procesos de gestión pública a través de la garantía de otros derechos como el acceso a la información y a los mecanismos de defensa, se abordan en este artículo, de una manera mucho más amplia, desde los estándares de justicia ambiental previstos en el ordenamiento jurídico para la toma de decisiones administrativas ambientales y no exclusivamente circunscrito a aquellos procedimientos que requieren consulta previa, justamente porque la pretensión de la investigación es mostrar que los alcances y la proyección constitucional de la participación como mandato de optimización, pilar estructural del Estado, derecho y deber desde las fuentes normativas analizadas, tales como instrumentos internacionales, jurisprudencia y desde la interacción de los procedimientos ambientales especiales con el procedimiento administrativo general previsto en la Ley 1437 de 2011, tienen la vocación de influir en la totalidad del ordenamiento jurídico y en las actuaciones de las autoridades públicas, cumpliendo con ello, una función dogmática y reconfiguradora del sistema ${ }^{7}$, en la medida en que permiten dotar de legitimidad democrática a las decisiones del Estado.

A partir de estas consideraciones metodológicas, se admite que, aunque con un estudio empíricos muy pertinente para este ámbito- es posible derivar conclusiones o hallazgos con referencia a la realidad de la expedición de las licencias ambientales y a la manera cómo se desarrolla fácticamente la garantía del principio de participación, desde los análisis dogmáticos, como el que se presenta, se pueden ofrecer opciones argumentativas para la comprensión y solución de problemas en este campo. Tal y como lo explica SchmidtAssmann,

los conceptos y las categorías de la teoría general habrán de someterse a una constante revisión [...]. En consecuencia, la dogmática supone a un tiempo la utilización del sistema establecido, de un lado y su construcción y revisión, de otro. ${ }^{8}$

Los hallazgos del estudio propuesto se organizan atendiendo a los acápites en que se divide el artículo. En una primera parte, se presenta un análisis de las transformaciones del DA a partir del Estado social y democrático de derecho; se acude para ello a algunas fuentes doctrinales pertinentes que han explicado dichas transformaciones desde el relacionamiento entre la Administración pública y del administrado. En una segunda parte, se estudian tales transformaciones desde el replanteamiento que supone el principio de participación para las técnicas unilaterales de la administración, ya no exclusivamente reconducibles por las lógicas del criterio del poder público.

En un tercer momento, atendiendo a la propuesta metodológica de Schmidt-Assmann, se analiza el Derecho Ambiental desde los fundamentos constitucionales y normativos, nacionales e internacionales, que asignan una relevancia especial a la protección ambiental como actividad de la Administración pública, y desde la reglamentación del procedimiento administrativo para la expedición de las licencias ambientales en Colombia, como un "sector de referencia" con potencialidad para catalizar las necesidades de reconfiguración de instituciones o categorías propias de la teoría general del DA. Se acude, en este sentido, al método sistemático e integrador que propone este autor en virtud del cual es posible, acudiendo a una metodología 
inductiva-deductiva, reconfigurar o reinterpretar instituciones básicas del derecho administrativo para, posteriormente, analizar los elementos de la licencia ambiental y concluir con las consecuencias que, para la validez y el carácter unilateral de las decisiones administrativas en materia ambiental, tendría el desconocimiento de la participación en el marco de una teoría del acto administrativo que atienda a las transformaciones que demanda el Estado social y democrático de derecho.

\section{Transformaciones del derecho administrativo desde el nuevo relacionamiento de la Administración pública y del administrado}

Tanto desde la doctrina nacional como desde la foránea del DA se ha hecho manifiesta la afirmación de la incidencia del Estado social y constitucional de derecho (ESCD) en esta disciplina y en la función administrativa ${ }^{9}$. Esta influencia ha sido explicada a partir de un análisis de las mutaciones del DA que como disciplina que se ocupa precisamente de la función administrativa, se enfrenta a una realidad constitucional en la que los principios constitucionales y los derechos fundamentales desempeñan un papel concluyente, como consecuencia de los roles y características que asume la Administración pública de cara a las finalidades que le exige este modelo de Estado ${ }^{10}$.

Estas transformaciones se han reflejado en una penetración del Estado en la vida social, el afianzamiento de políticas económicas y sociales por la vía normativa y en el establecimiento de nuevos modos de relacionamiento entre el Estado y los particulares. La incidencia de la participación en la concepción del DA había sido explicada desde antes por Muñoz al reconocer entre sus funciones, la de complementar las decaídas formas de legitimación externa al imponer una presencia viva y cualificada de los intereses comunitarios en el interior de la propia estructura administrativa y eliminar con ello la radical contraposición entre Estado y sociedad $^{11}$.

La actuación del Estado se ha hecho extensiva a sectores como la salud, la educación, la seguridad, el trabajo y, por supuesto, el medio ambiente y el territorio, entre otros; circunstancia que ha traído aparejada la adopción de nuevos compromisos, de tal manera que su función deja de concebirse bajo los postulados de la ideología política liberal como un rol meramente reducido a la garantía de los derechos y libertades del individuo, para ampliarse hacia una actuación determinada por la consagración jurídica en los textos constitucionales de obligaciones de carácter positivo. El Estado interviene como cogestor y, en todo caso, como regulador de lo público ${ }^{12}$. Se encuentran manifestaciones en las que lo público trasciende la institucionalidad pública y algunos asuntos de interés estatal llegan a proyectarse en lo privado, entre ellos, el medio ambiente ${ }^{13}$.

El lugar que encuentra el DA en estas transformaciones ha sido el de convertir el sistema jurídico en instrumento para intervenir los sistemas sociales, corregir los desequilibrios y regular las líneas que deben orientar las relaciones sociales. El DA se ha convertido así en el "instrumento primordial del Estado social de derecho y [en] un derecho de relaciones con la comunidad" ${ }^{14}$. El DA ha trascendido del carácter estrictamente normativista y formalista, hacia la idea de mecanismo facilitador, a fin de posibilitar la consecución de los fines e intereses sociales trazados por el Estado ${ }^{15}$.

Por lo anterior, las categorías centrales del DA no admiten en la actualidad representaciones uniformes, ni estáticas. Muestran alcances más amplios en torno al reconocimiento de sociedades participativas y pluralistas. Ejemplo de ello es la fundamentación clásica del principio de legalidad y su transmutación al principio de juridicidad caracterizado por una idea amplia de sometimiento de la administración al derecho ${ }^{16}$.

La consolidación de la supremacía constitucional en el paradigma de ESCD ha significado además de la sujeción a procedimientos y formas establecidos por el propio texto constitucional, una vinculación a los 
contenidos materiales que condicionan sustantivamente el ejercicio de la función administrativa al regular las formas de producción del derecho, imponer contenidos y orientar la actividad estatal:

en virtud de la cual no solo se define quién y cómo se debe ejercer el poder, sino también qué se debe decidir —en positivo, y ya no solo en negativo- y en qué dirección deben actuar los poderes públicos. ${ }^{17}$

Más allá de la descripción de las transformaciones de la disciplina administrativa es preciso plantear propuestas en la reconfiguración de sus instituciones a partir de la nueva concepción de la legalidad y de los matices que adquiere a partir de principios constitucionales como el de participación.

Estas propuestas han sido explicadas por autores como Schmidt-Assmann a partir de fenómenos como el de la constitucionalización del DA que, desde su carácter configurador del sistema supone considerar formas de relacionamiento en las que la administración abandona o disminuye su lugar de superioridad y autoridad frente a los administrados. Estas formas dan cuenta de una nueva posición del ciudadano y muestran la manera en que los principios constitucionales irradian y rematerializan las actividades, medios y fines propios de la administración pública y objeto del DA, uno de los cuales es el acto administrativo como instrumento propio del accionar administrativo.

La democracia y la participación como pilares del ESCD definen así el contenido particular de la vinculación jurídica de la administración y de su relación con los ciudadanos. Son, como lo señala García de Enterría, irreductibles a las instituciones públicas, a la definición de los poderes o del principio de libre elección, e inseparables de una teoría y práctica del derecho y, por supuesto, de la definición de los contenidos materiales del $\mathrm{DA}^{18}$.

\section{El principio de participación y la mutación de las técnicas unilaterales de la administración}

Una de las consecuencias más relevantes de las transformaciones del DA, se presenta en el ejercicio de las técnicas unilaterales, propias de su surgimiento y consolidación como un régimen especial, a partir de fundamentos como el poder público y el interés general.

En la búsqueda histórica de sustantividad para el concepto de DA y para la administración pública, el criterio de las prerrogativas públicas y la teoría que la sustenta se erigió en un punto cardinal para la interpretación y justificación de las funciones públicas en general, y en particular, para la organización del DA, su conceptualización y la explicación de la administración ante todo como un fenómeno de poder ${ }^{19}$.

Bajo esta perspectiva, se construyó una imagen de la administración pública como un personaje poderoso, titular de poderes exorbitantes ${ }^{20}$, que aunque institucionalizados bajo el principio de legalidad, son impropios para los particulares y se expresan de manera específica en la posibilidad de la imposición unilateral de sus decisiones, denominadas ejecutorias por su capacidad de aplicarse forzosamente como fundamento de la gestión administrativa indispensable para el cumplimiento de los intereses públicos.

En estos supuestos se configuran las categorías centrales para el DA, como el acto administrativo y la teoría que le da sistematicidad a sus elementos de existencia, validez, y a la unilateralidad que le caracteriza. La doctrina española explica estas características a partir de la capacidad de la administración pública de tutelar de manera autónoma los bienes jurídicos que le son atribuidos, también conocida como autotutela administrativa, con la finalidad de cumplir los cometidos estatales y garantizar el interés general. En virtud de la llamada autotutela:

La administración no requiere someter sus pretensiones a un juicio declarativo para hacerlas ejecutorias: sus decisiones son ejecutorias por su propia autoridad. Ella está exenta de juicios declarativos, pues su coacción es pública y no privada, por eso es legítima. ${ }^{21}$ 
Este privilegio encuentra explicación histórica en la necesaria separación de los asuntos administrativos de los de justicia, promovida en Francia luego de la Revolución y formalizada mediante la Ley 16 de 24 de agosto de 1790. En esta ley se prohibió a los tribunales interferir en los asuntos administrativos, lo que dio lugar a un régimen de sometimiento de control judicial de la Administración pública, que es posterior a las actuaciones administrativas, y que impide la suspensión de los efectos de las decisiones hasta la existencia de un pronunciamiento jurisdiccional ${ }^{22}$.

La formulación originaria de estos privilegios y prerrogativas a favor de la administración, se desarrolla a instancias del Estado de derecho y de la vinculación formal a la legalidad, que implicaba la existencia y justificación de una administración pública que asumía de manera monopolística los intereses generales y no requería de otro consentimiento distinto del propio para la formación de su voluntad y para la derivación de efectos jurídicos de esta.

Sin embargo, con la fórmula del ESCD cambian los presupuestos de la ejecutividad administrativa, otrora explicados en la idea de autotutela y en la acción unilateral dirigida a materializar y hacer efectivas de manera directa las decisiones administrativas.

La rigidez de la autotutela administrativa debe ser reconsiderada en los Estados contemporáneos, si se tiene en cuenta que en la configuración de lo que se entiende como interés general ya no interviene solamente la administración, sino también los particulares, quienes colaboran de manera concurrente en su satisfacción. Por tanto, con la formulación del ESCD, la consecución de las finalidades de interés general no es absorbida de manera exclusiva por el Estado, "sino que se armonizan en una acción mutua Estado-sociedad”23.

En esta transformación, entra en juego el ya indicado fenómeno de la constitucionalización, que se operativiza a través de su dimensión dogmática, al tomar en cuenta principios guía de la constitución, como el principio de participación, e investigar en qué medida estos deben ser erigidos en factores característicos del DA y de sus instituciones. La decisión constitucional a favor de la democracia y con ello del principio de participación, influyen en la construcción del sistema de DA a través de la obligación de legitimación y, ante todo, en la búsqueda del consenso en torno a las decisiones estatales ${ }^{24}$.

Así, bajo la impronta de los derechos humanos y de la relación democracia y administración, surgen formas de decisión caracterizadas por reglas más igualitarias de .relación e interlocución entre las autoridades y la sociedad" 25 que reflejan una ruptura con el arquetipo de administración soberana y el tránsito hacia una administración que posibilita la interlocución horizontal con los administrados como alternativa para la elaboración de "decisiones complejas, en escenarios diversos y plurales, que garanticen cohesión social y convivencia pacífica entre los administrados"26.

De este modo, la constitucionalización de la Administración pública, y con ello su democratización, va más allá de la garantía de legitimidad y se extiende a la forma en que se ejerce la actividad administrativa, al estilo de administrar y al procedimiento para la configuración de las decisiones administrativas en el que, como propone Schmidt-Assmann, no pueden seguir estimándose como antijurídicos aquellos ámbitos en los que la participación de los interesados en la formación de la decision trasciende la mera colaboración hacia una auténtica codecisión ${ }^{27}$.

$\mathrm{Al}$ respecto, Barnés alude a tres generaciones del procedimiento administrativo para ilustrar los cambios en el relacionamiento de la administración con los administrados en lo que respecta a la formación de los actos administrativos. Esas generaciones hacen referencia a los distintos modos en que opera la administración pública y permiten visualizar la flexibilización de sus técnicas unilaterales, como consecuencia del principio de participación. Se trata de modalidades de procedimiento que se suceden en el desenvolvimiento histórico de la administración y que coexisten en la práctica ${ }^{28}$.

La administración pública de la primera generación del procedimiento administrativo es una administración de estilo jerárquico que resuelve los asuntos y adopta decisiones investida de autoridad y de manera vertical. La segunda generación es una administración también imperativa que dicta normas de 
manera similar al legislador cuando elabora disposiciones reglamentarias, planes, proyectos, programas. La tercera generación de administración se caracteriza por incorporar en la formación de sus decisiones formas de gobernanza, marcadas por la colaboración y la adopción consensuada de decisiones, en las que la participación de los particulares es fundamental para construir una mejor decisión ${ }^{29}$.

En cada una de estas modalidades, el principio de participación se encuentra presente con distintas intensidades y funciones, dependiendo del rol que desempeña la administración en los diversos procedimientos que constituyen campos para el ejercicio de la función administrativa.

La labor de la administración de la primera modalidad es estrictamente ejecutiva, se limita a aplicar el derecho y por ello se le califica como autosuficiente. Si existe una participación de los administrados en este escenario, se subsume en el ejercicio de audiencia y contradicción. En el proceso de evolución del DA, esta tipología de administración corresponde con el surgimiento y consolidación de instituciones como el procedimiento administrativo ${ }^{30}$. Aunque la administración se identifica con el uso de potestades públicas, y resuelve, de manera unilateral, la institucionalización del procedimiento administrativo, permite definir una forma de relacionamiento y garantizar la posición jurídica con los ciudadanos, como lo explica Araujo a partir de una reseña de las primeras normas que rigieron el procedimiento administrativo en Colombia a finales del siglo $\mathrm{XX}^{31}$.

En la segunda modalidad de administración, la participación de los administrados se muestra ante todo a partir de su colaboración en actividades y sectores antes exclusivos del Estado, como la formulación de planes y programas. La participación de los ciudadanos y de los interesados en la adopción de la decisión se muestra y se consolida aquí como una garantía propia del debido proceso administrativo y de un prototipo de procedimiento con garantías aplicable a la actividad administrativa para la formación del acto administrativo.

El principio de participación en la tercera generación del procedimiento administrativo desempeña - a diferencia de los procedimientos anteriores - un papel con respecto a la colaboración entre los particulares y la Administración pública para la configuración de las decisiones administrativas, que no solo están relacionadas con la garantía del debido proceso, sino con la aplicación de fórmulas de deliberación y concertación con grupos de ciudadanos, con el propósito de alcanzar objetivos de interés público ${ }^{32}$, garantizar la eficacia de la actividad administrativa ${ }^{33}$ y las buenas prácticas de gobierno y administración ${ }^{34}$.

De acuerdo con la propuesta de Schmidt-Assmann, "[d]e cara al estudio de las posibilidades de participación deben analizarse las distintas formas en las que la actividad administrativa afecta al ciudadano" ${ }^{35}$. De manera que la posición jurídica del ciudadano y el ámbito en el que la administración toma las decisiones repercuten en las consecuencias dogmáticas que se derivan del principio de participación. En este sentido, las decisiones en materia ambiental y, en particular, las relacionadas con las licencias ambientales, se constituyen en un sector de referencia indicativo para evidenciar las transformaciones en la formación unilateral de las decisiones administrativas.

Así, el principio de participación, visto desde la propuesta de generaciones de procedimientos administrativos, se presenta como un dispositivo que revela la mutación de las técnicas unilaterales de la administración y se activa en diferentes momentos de la formación de la decisión administrativa, cumpliendo funciones diversas y con la vocación de impactar distintos elementos del acto administrativo, ya no exclusivamente susceptible de ser encauzada a través del elemento formal del acto y del debido proceso, sino a partir de la relevancia contemporánea de las decisiones que debe adoptar la administración en materia ambiental y de la participación de los afectados como presupuesto indisponible en la formación de la voluntad administrativa. 


\section{El derecho ambiental como un "sector de referencia" y catalizador de las necesidades de reforma de la teoría general del derecho administrativo}

La propuesta de reforma del DA de Schmidt-Assmann pone su acento en el método de construcción y estudio de esta disciplina jurídica especial ${ }^{36}$. Desde la perspectiva sistemática que plantea este autor, la comprensión de las transformaciones estructurales del DA solo es posible efectuarla a partir del análisis de campos específicos de estudio que están en constante movimiento y evolución.

Estos campos son los que reconoce como sectores de referencia, que integran la conocida dogmáticamente parte especial del DA, que comprende entre otros, los distintos procedimientos administrativos especiales. La idea de ámbitos de referencia implica, de este modo, superar la división estricta entre la parte general y la parte especial del DA y avanzar en un conocimiento dialógico en el que las bases e instituciones estructurales de esta disciplina se nutren de manera permanente e interactúan recíprocamente con la parte especial a través de un proceso inductivo-deductivo ${ }^{37}$.

Los procesos inductivos permiten construir y enriquecer la teoría general, pero también poner a prueba sus bases a partir del análisis de los fines e intereses que persigue la función administrativa en cada caso. Por ello, Schmidt-Assmann destaca las potencialidades del derecho ambiental como un sector para identificar distintas esferas de la acción administrativa y estudiar su evolución y correspondencia con las categorías dogmáticas de la parte general.

En la esfera ambiental se evidencian facetas de la acción administrativa que van desde la policía administrativa, el servicio público, la gestión de los bienes públicos, los riesgos y la responsabilidad, entre otros. Muchas de estas se canalizan por medio del procedimiento administrativo como un campo ilustrativo para analizar la repercusión de la participación en procesos decisorios creativos, innovadores y con una visible apertura a la deliberación necesaria para la configuración de la decisión administrativa ${ }^{38}$.

El derecho ambiental constituye, además, un ámbito en el que es posible identificar "el alcance de la infiltración que se ha operado en el derecho administrativo por parte del derecho internacional público y, más precisamente, en el derecho procedimental administrativo nacional" ${ }^{39}$. El derecho ambiental, visto desde la perspectiva del DA, conjuga una variedad de procedimientos orientados al cumplimiento de los deberes y fines del Estado de proteger el ambiente y los recursos naturales como patrimonio común, de conservar áreas que por sus condiciones biológicas, genéticas, estéticas, socioeconómicas y culturales deben perdurar, atendiendo a su especial importancia ecológica para las comunidades y para los mismos ecosistemas, y, en general, de procurar el desarrollo y la calidad de vida de las personas, como un presupuesto básico del Estado social y ambiental del derecho ${ }^{40}$.

En el contexto colombiano, el ambiente, como parte de la actividad administrativa, ocupa un lugar transversal en el ordenamiento jurídico y es un presupuesto para el perfeccionamiento de la democracia ${ }^{41}$. Se exhibe desde el preámbulo mismo de la Constitución (C.P. Colom., art. $1^{\circ}$ ) y la declaración de los fines estatales (C.P. Colom., art. $2^{\circ}$ ); en la consagración de la obligación del Estado y de las personas de proteger las riquezas culturales y naturales de la nación (C.P. Colom., arts. $8^{\circ}$ y 95), así como en el deber del Estado de planificar el manejo, aprovechamiento sostenible de esos recursos, su conservación, sustitución y restauración.

Del mismo modo, en el deber de intervenir en la economía para la preservación del ambiente sano y en la consideración del ambiente como límite a la libertad económica (C.P. Colom., arts. 8, 333 y 334); en la definición del saneamiento ambiental como servicio público y finalidad social del Estado (C.P. Colom., arts. 49 y 366); en el reconocimiento de la función ecológica de la propiedad y del carácter inalienable, imprescriptible e inembargable de una serie de bienes que incluyen el patrimonio ambiental, así como de la propiedad estatal del subsuelo y de los recursos naturales no renovables (C.P. Colom., arts. 58, 63 y 332); en el derecho y deber a la educación ambiental (C.P. Colom., art. 67); y, por supuesto, en la consagración expresa del derecho a gozar de un ambiente sano con la correlativa obligación del legislador de garantizar 
la participación de la comunidad en las decisiones que les puedan afectar (C.P. Colom., art. 79). A su vez, en un conjunto de disposiciones que, desde el punto de vista orgánico, determinan el diseño de toda una institucionalidad pública con funciones administrativas en la materia (C.P. Colom., arts. 150-7; 212; 226; 267, 268, 277, 289, 300-2, 310, 313-9, 317, 330, 331).

No obstante, en la particularidad de los procedimientos especiales en materia ambiental — que se manifiesta por ejemplo en la aplicación de principios autónomos-, muchos de ellos que orientan el Sistema Nacional Ambiental del Estado ${ }^{42}$, se evidencia una permanente relación con el procedimiento general ${ }^{43}$, aspecto que demuestra tanto el carácter subsidiario y complementario del procedimiento general, como la interrelación a la que alude Schmidt-Assmann. Uno de esos principios es el de participación, cuya estructura se encuentra formalizada en la legislación del procedimiento administrativo general, pero que desempeña una función peculiar en el otorgamiento de licencias ambientales, en tanto que la participación del ciudadano se produce no solo cuando es afectado por las decisiones de la administración, sino cuando participa en los estadios de configuración de la voluntad de la decisión, a través de proyectos que pueden tener incidencia en toda la comunidad $^{44}$.

El principio de participación en el ordenamiento jurídico colombiano, se entiende como un elemento axial del orden jurídico es tanto un principio, un fin estatal, un derecho fundamental, un deber y un mecanismo de carácter transversal que permite el ejercicio de la ciudadanía, en tanto se relaciona con la visión y posición que adquiere el ciudadano en la Constitución de 1991 con respecto al Estado, como sujeto político cuya capacidad no se agota en la elección de sus representantes, sino que se extiende hacia todos los procesos decisorios que puedan afectarlo ${ }^{45}$.

La licencia es un acto administrativo que otorga a su destinatario el derecho a realizar un proyecto, obra o actividad que genere efectos sobre los recursos naturales renovables, el medio ambiente o que tenga la potencialidad de introducir modificaciones considerables o notorias al paisaje. Este acto administrativo sujeta al beneficiario al cumplimiento de los requisitos, términos, condiciones y obligaciones en relación con la prevención, mitigación, corrección, compensación y manejo de los efectos ambientales del proyecto, obra o actividad autorizada, de conformidad con las condiciones técnicas establecidas por la autoridad competente ${ }^{46}$.

El Decreto 2041 de 2014, actualmente incorporado al Decreto Único Reglamentario del Sector Ambiente, Vivienda y Desarrollo Sostenible, reglamenta el Título VIII de la Ley 99 de 1993 sobre licencias ambientales y contempla de manera general la participación de las comunidades, a partir del deber de informar el alcance del proyecto, con énfasis en los impactos y las medidas de manejo, las propuestas y la valoración e incorporación en el estudio de impacto ambiental, cuando se consideren pertinentes, de los aportes recibidos durante este proceso $^{47}$.

En sectores específicos como el minero, la legislación no contempla una intervención y participación activa de las comunidades y autoridades territoriales, como muestra de la prevalencia allí del carácter unilateral de las decisiones administrativas, en razón al establecimiento constitucional de la propiedad del Estado sobre el subsuelo (C.P. Colom., art. 332) y a su identificación como actividad de utilidad pública ${ }^{48}$. De tal modo que la posibilidad de participación ha sido eje de tensiones entre las autoridades administrativas y las comunidades ${ }^{49}$.

Sin embargo, por la vía jurisprudencial se ha afianzado la obligación estatal consagrada en el artículo 79 de la Carta Política y en el Principio 10 de la Declaración de Río de Janeiro de 1992, de garantizar la participación efectiva de la población que potencialmente pueda ser afectada por el desarrollo de un proyecto minero o de otra índole ${ }^{50}$.

Así, desde instrumentos internacionales ${ }^{51}$, se ha identificado como prioritaria la garantía de derechos procedimentales que impactan la forma en la que se concibe la gobernanza y la democracia ambiental, y que contribuyen a la protección ambiental y a la prevención de conflictos, pues cuando las personas pueden informarse e incidir en la conformación de las decisiones que las afectan, se aumentan las posibilidades de que esas decisiones garanticen su derecho a gozar de un ambiente sano ${ }^{52}$. 
Esta participación se entiende garantizada cuando se cumplen como mínimo las siguientes fases que constituyen, en sí mismas, estándares para verificar su cumplimiento: a) convocatoria pública de los posibles afectados; b) información adecuada sobre la decisión o ejecución del proyecto que incluye el suministro de los datos, documentos, hechos, nociones y mensajes mediante los cuales los ciudadanos construyen su propio criterio; c) la consulta e iniciativa, que implica que los participantes emiten su opinión, juicio o análisis sobre el asunto de debate y formulan opciones así como alternativas al problema para resolver la situación; d) la concertación razonada sobre el objeto de debate en la planificación y ejecución del proyecto, que implica el acuerdo o consenso entre varias personas o grupos de la sociedad con el fin de adoptar la solución adecuada para el escenario planteado; e) la decisión, en la que se escoge una sugerencia de las varias alternativas propuestas para definir el plan de acción a seguir sobre un problema y se incorporan los resultados del consenso. Y, por último, con las fases de f) gestión y g) fiscalización, que permiten verificar y hacer seguimiento a las obligaciones derivadas del acto administrativo ${ }^{53}$.

Por tanto, más allá del deber formal de proporcionar la información relacionada con los proyectos de cualquier índole, los procedimientos que conduzcan a la obtención de un acto administrativo especial, como la licencia ambiental, exigen un análisis sustancial que no ha sido efectuado desde la incidencia del principio de participación, pues si bien, como actos administrativos gozan del atributo de la unilateralidad que determina que para su formación la autoridad administrativa competente no requiere más que su consentimiento o su declaración de voluntad para que el acto produzca efectos jurídicos, el deber de protección ambiental y los procesos de búsqueda de desarrollo sostenible desde el concepto de justicia ambiental, así como los criterios señalados demuestran una notable exigencia de participación, influenciada desde el derecho internacional, en relación con el desarrollo del vínculo entre derechos humanos y medio ambiente ${ }^{54}$.

El escenario de referencia de los procedimientos administrativos para la expedición de licencias ambientales, es representativo entonces de uno de los campos para el estudio dogmático del DA en Colombia y lo sitúa como un referente catalizador de sus necesidades de reforma, en la medida en que permite discutir y replantear cambios funcionales de la actividad administrativa y los desafíos que tiene la administración pública frente a la participación efectiva de los administrados en las decisiones que los afectan.

\section{Los elementos del acto administrativo, la garantía del principio de participación en las licencias ambientales y las consecuencias para su validez}

El ejercicio de la participación en materia ambiental ha sido ampliamente estudiado por autoras como Muñoz y Rodríguez que, desde el derecho ambiental, han resaltado la importancia de este principio en la actuación de la institucionalidad ambiental ${ }^{55}$. A su vez, el tema de las licencias ambientales ha sido objeto de aproximaciones enfocadas en su efectividad ${ }^{56}$. A diferencia de estos trabajos, en el presente artículo se examina la licencia ambiental desde la perspectiva del DA y, concretamente, de la teoría del acto administrativo ${ }^{57}$. Por esta vía se reconoce que la licencia ambiental es ante todo una "decisión especial, que no fácilmente puede recibir el examen típico de legalidad" 58 . Por ello, se analizan los elementos de esta categoría que se encuentran en mayor medida afectados por la incidencia de la participación efectiva de los administrados, entendida desde los estándares de justicia ambiental previstos en el ordenamiento jurídico para la toma de decisiones administrativas ambientales.

Si bien existe una normativa propia que reglamenta la expedición de las licencias ambientales en Colombia, no se señala en esta normativa cuáles serían los elementos estructurales de la licencia ambiental como acto administrativo, por lo que resulta necesario acudir a su análisis desde la llamada teoría general, que se ocupa de estudiar sus elementos estructurantes, sus atributos y sus consecuencias respecto de los vicios invalidantes. 
La doctrina no ha sido pacífica en cuanto a la noción de acto administrativo ${ }^{59}$ como lo muestran los distintos criterios (formal, orgánico, material, por ejemplo), que han permitido su aproximación. Se le ha atribuido por lo general un significado referido a las declaraciones unilaterales de voluntad de la administración, que producen efectos jurídicos subjetivos ${ }^{60}$ con el fin de distinguirlo del género de los actos de la administración. Este significado desde la perspectiva de autores como Sayagués excluye los actos convencionales de la administración de los cuales el más representativo es el contrato estatal ${ }^{61}$.

Las licencias ambientales se estructuran como cualquier acto administrativo a partir de los elementos subjetivo, objetivo, causal, formal y finalístico. Estos elementos responden, respectivamente, por el quién, el qué, el por qué, el cómo y el para qué de la decisión administrativa. A su vez, la doctrina denomina como vicios invalidantes a aquellas "circunstancias, acciones u omisiones, que una vez producidas le restan legalidad a la manifestación de voluntad de la administración" ${ }^{62}$. Estas circunstancias se recogen en el CPACA en el artículo 137, que define las causales para acudir al medio de control de nulidad ante la Jurisdicción Contencioso Administrativa, y su estudio está por tanto ligado al de los elementos del acto administrativo.

El elemento subjetivo se refiere al sujeto activo o emisor del acto, esto es, al sujeto competente de acuerdo con el ordenamiento jurídico para expedir la decisión administrativa y manifestar la declaración de voluntad. En este elemento se analizan los factores material, temporal, territorial y de grado. La competencia implica determinar quién es el sujeto habilitado por el ordenamiento jurídico para exteriorizar la decisión estatal luego de un proceso cognitivo a través del cual se configura la voluntad administrativa. En Colombia, la competencia para la expedición de las licencias ambientales está asignada a la Autoridad Nacional de Licencias Ambientales, a las Corporaciones Autónomas Regionales y a los municipios, distritos y áreas metropolitanas, cuando la población es superior a un millón de habitantes dentro de su perímetro urbano ${ }^{63}$.

Ahora bien, como ha señalado, la jurisprudencia constitucional ${ }^{64}$, la participación es un presupuesto sine qua non para garantizar el derecho al ambiente sano por medio de cualquier medida adoptada por la administración, y dicha participación solo es posible concretarla a partir de la integración de la legislación ambiental con la Constitución, las normas sobre el procedimiento general ${ }^{65}$ y los instrumentos internacionales que han determinado sus alcances ${ }^{66}$, así como los requisitos para su garantía, los cuales incorporan una necesaria deliberación, concertación y consenso para la adopción de la decisión ${ }^{67}$. Esto quiere decir que en el elemento subjetivo puede instalarse el principio de participación para mediar en el proceso volitivo a cargo de la autoridad competente. Esto transforma el proceso de configuración de la voluntad, de un proceso individual y exclusivo de la autoridad pública a un proceso que es "el resultado de un entrelazamiento de relaciones comunicativas" ${ }^{\text {, }}$, en el cual la voluntad de la administración debe vincular la participación de la comunidad, la voz de los afectados a partir de su conocimiento local.

El análisis de la incidencia del principio de participación en el elemento subjetivo del acto es una consecuencia de la transformación de la posición jurídica de los administrados en esta clase de procedimientos, que no se observan como simples destinatarios de la decisión, sino como coadyuvantes de esta.

Por su parte, el elemento objetivo está relacionado con la declaración de voluntad de la Administración, con el contenido y el objeto propiamente dicho de esa declaración. El Decreto 1076 de 2015 señala cuál es el contenido de la licencia ambiental, compuesto por la identificación del beneficiario, el objeto del proyecto y su localización, las consideraciones o motivaciones que serán tenidas en cuenta, los recursos naturales que se explotarán o aprovecharán, entre otros ${ }^{69}$. En correspondencia con el elemento subjetivo, el objeto del acto, es decir, lo que la autoridad ambiental en el caso disponga u ordene en relación con la autorización o no de las licencias y con las correspondientes cargas y obligaciones para el beneficiario, debe en todo caso incluir los elementos aportados y consensuados con la comunidad. De ahí que la participación, garantizada a través de las fases indispensables para su garantía, se torne en un parámetro para determinar la licitud del objeto.

El elemento causal, por su parte, alude a los motivos o causas que dieron lugar a la decisión a partir de la determinación de las circunstancias fácticas o antecedentes de hecho, los fundamentos jurídicos y la 
valoración efectuada por la autoridad ambiental para adoptar la decisión y determinar el objeto de esta. En el caso de las licencias ambientales, la garantía de la participación se entiende como la apertura de verdaderos espacios de diálogo con las comunidades afectadas. Esto significa que, para este elemento del acto, la participación no se agota con la socialización o la información, puesto que implica la construcción de un consenso razonado sobre las afectaciones y las medidas de compensación y mitigación.

Esto significa que las autoridades, al momento de emitir la decisión, deberían tener en cuenta los argumentos esbozados en la deliberación, valorar y evaluar las razones de la comunidad y justificar de manera ponderada en aquellos casos en los que se apartaron de las propuestas ${ }^{70}$. Las razones o motivos para la expedición de las licencias ambientales deben atender no solo a los informes y documentos técnicos necesarios para todo proyecto. Deben contemplar el análisis de los resultados de la participación de la comunidad a través de las diferentes fases y ser consecuentes con la deliberación y los acuerdos concertados.

El elemento formal tiene que ver con la forma, las formalidades y el procedimiento. La licencia ambiental es un acto que está precedido de una fuerte procedimentalización. Se trata de un acto que debe documentarse por escrito y surtir el procedimiento especial previsto en los artículos 2.2.2.3.6.1 y siguientes del Decreto 1076 de 2015, que contempla tanto las reglas para la obtención, como para la suspensión y renovación. Además de la autorización para la realización del proyecto, la licencia incluye los permisos, autorizaciones y concesiones para el uso, aprovechamiento y afectación de los recursos naturales renovables que sean necesarios para su desarrollo.

No obstante, al tratarse de un acto detalladamente normado, la decisión se adopta de manera discrecional por la autoridad ambiental, en la medida en que el procedimiento que da lugar a su expedición permite evaluar diferentes insumos, como el estudio de impacto ambiental o el diagnóstico ambiental de alternativas, así como consultar a otras autoridades y posibilitar la participación de la ciudadanía que también pueden aportar pruebas, documentos e información, que la autoridad deberá valorar y ponderar entre las mejores opciones posibles $^{71}$. Esto supone un proceso evaluativo en el cual la autoridad debe tomar una decisión motivada, que incluso puede llevar a la negación de la autorización, de acuerdo con la viabilidad socioambiental del proyecto.

El análisis del principio de participación se ha ubicado tradicionalmente en el elemento formal de la licencia ambiental, esto es, como parte del procedimiento administrativo y como un presupuesto para la controversia, la transparencia, la imparcialidad o la defensa de los interesados en la actuación administrativa, aspecto que sin duda implica, como lo plantea J.\#O. Santofimio, un abandono de cualquier plano de arbitrariedad y de ejercicio de poder y un elemento vital para la consolidación de instituciones democráticas ${ }^{72}$.

Sin embargo, en el caso de los procedimientos administrativos para las licencias ambientales, como se ha dejado señalado, el ejercicio de la participación no parece que se deba reducir a la garantía del derecho de audiencia y contradicción como componente del debido proceso administrativo que se debe garantizar a los afectados del proyecto, de acuerdo con las reglas específicas que contempla el Decreto 1076 de 2015, sino que debe hacerse extensivo y con carácter vinculante en todas las fases que componen un auténtico ejercicio participativo relacionadas con la convocatoria, información, la consulta e iniciativa, la concertación, la decisión, la gestión y la fiscalización.

Por último, el elemento finalístico está asociado al objetivo que persigue la autoridad administrativa, que en términos genéricos es el interés general. En el caso particular de las licencias ambientales, este interés general no es otro que garantizar la protección de los recursos naturales y el medio ambiente, conservar áreas de especial importancia ecológica, prevenir y controlar el deterioro ambiental y realizar la función ecológica de la propiedad, procurando que los proyectos, obras o actividades generen el menor impacto posible ${ }^{73}$. También tiene como finalidad asegurar que las actividades humanas y económicas garanticen el desarrollo sostenible, de ahí que también tenga un propósito preventivo o precautelativo en la medida en que busca eliminar, disminuir o mitigar los efectos nocivos de una actividad sobre el medio ambiente. Por ello, las licencias constituyen una manifestación de la intervención del Estado en la economía y una limitación a la iniciativa privada, justificada 
en la obligación de garantizar la función ecológica ${ }^{74}$. Estas finalidades, como ya se ha señalado, no pueden lograrse sin la participación de las comunidades, que además de incorporarse por esta vía a las finalidades del acto, constituye una garantía de eficacia y de buena administración.

\section{Conclusiones: las consecuencias dogmáticas de la participación en el procedimiento administrativo de expedición de licencias ambientales}

Los procedimientos ambientales para la expedición de las licencias ambientales constituyen uno de los escenarios de actuación estatal especialmente imbricados por el derecho internacional, aspecto que ha fortalecido desde el punto de vista dogmático la repercusión de la participación de los administrados en la formación de decisiones administrativas en el ámbito ambiental. Esto amerita, para este campo de la actuación administrativa, una revisión y reformulación de la teoría tradicional del acto administrativo, por los matices que atenúan los caracteres de poder público tradicional de la administración pública.

El carácter humano del derecho al ambiente, cuya efectividad reclama de manera inevitable la participación de las comunidades en la adopción de decisiones implica que, en la conformación de la voluntad administrativa para la expedición de licencias ambientales, deba estar incorporada la voluntad de los administrados y que, en tales casos, no sea posible generalizar el carácter unilateral de los actos administrativos, y confirmar la necesidad de plantear una teoría del acto administrativo adaptable a las particularidades del ordenamiento jurídico colombiano. Esta característica, sin embargo, no convierte a tales actos -las licencias - en actos convencionales, ni les despoja de su carácter de acto administrativo, pero sin duda flexibiliza uno de los atributos típicos de la administración pública que la identificaron históricamente como un fenómeno de poder, que pueden convertirse en instrumentos de la gobernanza y la democratización de la administración como gestora de los intereses de la colectividad.

El análisis del principio de participación, y su incidencia en los elementos de la decisión sobre la licencia ambiental, permite derivar consecuencias dogmáticas frente a la validez de los actos que se expidan sin satisfacer los estándares de participación ambiental señalados, más allá del vicio por expedición irregular por afectación de su elemento formal. En realidad, deja abierta la posibilidad para plantear la configuración de otros vicios instalados en el elemento competencial, o en el objetivo a la manera de objeto ilícito, e incluso la desviación de poder, cuando la configuración del interés general en cada caso en concreto no estuvo mediada por la intensa participación de los administrados.

\section{Bibliografía}

Alberto Montaña \& Andrés Ospina, eds., La constitucionalización del derecho administrativo (Universidad Externado de Colombia, 2014).

Andrés Briceño, Responsabilidad y protección del ambiente: la obligación positiva del Estado (Universidad Externado de Colombia, 2017).

Andrés F. Ospina, La eficacia en el derecho administrativo colombiano: de advenediza a reina. Reflexiones a partir de la obra de Eberhard Schmidt-Assmann, en J. O. Santofimio, J. Barnés \& M. L. Ibagón, eds., Perspectivas de una reforma. Estudios de derecho administrativo a partir de la obra de Eberhard Schmidt-Assmann (Universidad Externado de Colombia, 2016).

Andrés Gómez, Gloria Rodríguez \& Iván Vargas. De la nulidad y el restablecimiento del derecho: La complejidad que supone el éxito de los medios de control sobre los actos administrativos relacionados con la licencia ambiental 223-247, en G. Rodríguez, ed., Justicia Ambiental en Colombia: ejercicio participativo a través de las acciones constitucionales (Ibáñez, 2018). 
Atlas de Justicia Ambiental EJOLT: Environmental Justice Organizations, Liabilities and Trade, http://www.ejolt.or g/project/ [consultado: 4 de mayo de 2020].

Augusto Hernández, Administración pública, derecho administrativo y constitución 43, en $\mathrm{H}$. Arenas, Instituciones de derecho administrativo, tomo I (Ed. Ibáñez, Universidad del Rosario, 2016).

Carolina Moreno, Derecho administrativo y neoliberalismo: narrativa de una relación, en nuevas tendencias del derecho administrativo 101-119, en H. Alviar, coord. (Universidad de los Andes, Temis, 2016).

CEPAL. Acuerdo de Escazú. Acuerdo Regional sobre el Acceso a la Información, la Participación Pública y el Acceso a la Justicia en Asuntos Ambientales en América Latina y el Caribe. 2018.

Christian Courtis, El juego de losjuristas. Ensayo de caracterización de la investigación dogmática 106, en C. Courtis \& A. Manuel, eds., Observar la ley: ensayos sobre metodología de la investigación jurídica 183-122 (Ed. Trotta, 2006).

CoIDH. Opinión Consultiva OC-23/17. Solicitada por la República de Colombia. 15 noviembre 2017.

Colombia. Decreto 1076 de 2015. Por medio del cual se expide el Decreto Único Reglamentario del Sector Ambiente y Desarrollo Sostenible. Mayo 26 de 2015. D.O. núm. 49.523.Colombia. Ley 1437 de 2011. Por la cual se expide el Código de Procedimiento Administrativo y de lo Contencioso Administrativo, enero 18 de 2010. D.O. núm. 47.956 .

Colombia. Ley 1955 de 2019. Por la cual se expide el Plan Nacional de Desarrollo 2018-2022. "Pacto por Colombia, Pacto por la Equidad". Mayo 25 de 2019. D.O. núm. 50.964.

Colombia. Ley 685 de 2001. Por la cual se expide el Código de Minas y se dictan otras disposiciones. Agosto 15 de 2021. D.O. 44.545.

Colombia. Ley 99 de 1993. Por la cual se crea el Ministerio del Medio Ambiente, se reordena el Sector Público encargado de la gestión y conservación del medio ambiente y los recursos naturales renovables, se organiza el Sistema Nacional Ambiental, SINA y se dictan otras disposiciones. Diciembre 22 de 1993. D.O. núm. 41.146

Constitución Política de Colombia [C.P.], julio de 1991 (Colom.).

Contraloría General de la República, El proceso administrativo de licenciamiento ambiental en Colombia (2017).

Convención Americana sobre Derechos Humanos.

Convención Marco de las Naciones Unidas sobre el Cambio Climático, 1992.

Convenio sobre la Diversidad Biológica, 1992.

Corte Constitucional de Colombia [C.C.], mayo 15, 2012, M.P.: Jorge Ignacio Pretelt, Sentencia T-348, [Colom.].

Corte Constitucional de Colombia [C.C.], mayo 22, 2014, M.P.: María Victoria Calle Sentencia T-294, [Colom.].

Corte Constitucional de Colombia [C.C.], mayo 30, 2017, M.P.: Alberto Rojas, Sentencia T-361, [Colom.].

Corte Constitucional de Colombia [C.C.], noviembre 1 ${ }^{\circ}$, 2016, M.P.: Luis Ernesto Vargas, Sentencia T-599, [Colom.].

Corte Constitucional de Colombia [C.C.], octubre 23, 2015, M.P.: Jorge Ignacio Pretelt, Sentencia T-660, [Colom.].

Corte Constitucional de Colombia [C.C.], octubre 7, 2003, M.P.: Rodrigo Escobar, Sentencia C-894, [Colom.].

Declaración Americana de los Derechos y Deberes del Hombre, 1948.

Declaración de Río de Janeiro sobre el Medio Ambiente y el Desarrollo de la Conferencia de las Naciones Unidas sobre el Medio Ambiente y el Desarrollo, 1992.

Declaración Universal de los Derechos Humanos, 1948.

Diana Carolina Sánchez Zapata \& Hernán D. Vergara Mesa, Procedimiento administrativo y posacuerdo: el principio de participación en la formación de las decisiones administrativas, 17 (35) Opinión Jurídica 185-208 (2018), https: //doi.org/10.22395/ojum.v17n35a8

Eberhard Schmidt-Assmann, La teoría general del derecho administrativo como sistema. Objeto y fundamentos de la construcción sistemática (Marcial Pons, Ediciones Jurídicas y Sociales, 2003).

Eberhard Schmidt-Assmann. El concepto de la constitucionalización del derecho administrativo, en A. Montaña \& A. Ospina, eds., La constitucionalización del derecho administrativo. XV Jornadas Internacionales de Derecho Administrativo 21-38 (Universidad Externado de Colombia, 2014).

Eduardo García de Enterría \& Tomás Ramón Fernández, Curso de derecho administrativo, vol. 1 (Ed. Civitas, 1993). 
Eduardo García de Enterría. Democracia, jueces y control de la administración (4... ed., Ed. Civitas, 2004).

Enrique Sayagués, Tratado de derecho administrativo, tomo I, 382 y 389 (6. ${ }^{a}$ ed., Fundación de Cultura Universitaria, 1988).

Erika Castro, Derecho ambiental y gobernanza 25 (Sello Editorial Universidad de Medellín, 2017).

Fabián Marín, Público privado. Estudio sobre las transformaciones del derecho, del Estado y de la Empresa (Temis, 2008).

Gloria Rodríguez, Autorizaciones y procesos administrativos y ambientales 415-454, en $\mathrm{H}$. Arenas, Instituciones de derecho administrativo, tomo I. La administración y su actividad (Universidad del Rosario, Ibáñez, 2016).

Gloria Rodríguez, Problemáticas y elementos asociados al proceso administrativo para el otorgamiento de licencias en Colombia 357-385, en M. Restrepo, ed., Derecho administrativo. Reflexiones contemporáneas (Universidad del Rosario, 2017).

Gustavo Ortega, Constitucionalismo ambiental y derechos ambientales: análisis de la evolución del Estado ambiental de derecho, el ambientalismo y la formación del precedente judicial ambiental 43-123, en G. Mesa, Derechos ambientales en disputa: algunos estudios de caso sobre conflictividad ambiental (Universidad Nacional de Colombia, 2015).

Héctor Santaella, Del principio de legalidad al principio de juridicidad: implicaciones para la potestad normativa de la administración de una transición constitucionalmente impuesta 79-115, en A. Montaña \& A, Ospina, eds., La constitucionalización del derecho administrativo. XV Jornadas Internacionales de Derecho Administrativo (Universidad Externado de Colombia, 2014).

Hugo Marín, El procedimiento administrativo como herramienta para la paz, en A. Montaña, \& A. Ospina, eds., La constitucionalización del derecho administrativo (Universidad Externado de Colombia, 2014).

Jaime O. Santofimio, Compendio de derecho administrativo (Universidad Externado de Colombia, 2017).

Jaime O. Santofimio, Fundamentos de los procedimientos administrativos en el Código de Procedimientos Administrativo $y$ de lo Contencioso Administrativo - Ley 1437 de 2011- 145-186, en Memorias Seminario Internacional de presentación del Nuevo Código de Procedimiento Administrativo y de lo Contencioso Administrativo. Ley 1437 de 2011 (Imprenta Nacional de Colombia, 2012).

Jaime O. Santofimio, Tratado de derecho administrativo, acto administrativo, procedimiento, eficacia y validez 355 (4.. ed., Universidad Externado de Colombia, 2003).

Javier Barnés, Buena administración, principio democrático y procedimiento administrativ., 21 Revista Digital de Derecho Administrativo 77-123 (2019).

Javier Barnes, Tres generaciones de procedimiento administrativo 120-164, en P. Aberastury \& H. Blanke, eds., Tendencias actuales del procedimiento administrativo en Latinoamérica y Europa. Presentación de la traducción de la Ley alemana de procedimiento administrativo, (Fundación Konrad Adenauer, Eudeba, 2011).

José L. Meilán. Maurice Hauriou en perspectiva, en A. Matilla, J. O. Santofimio \& H. Santaella, Ensayos de derecho público. En memoria de Maurice Hauriou (Universidad Externado de Colombia, 2013).

Juliette Sleman-Chams \& Carlos J. Velásquez-Muñoz, La licencia ambiental: ¿instrumento de comando y control por excepción?, Vniversitas 483-514 (2016), http://dx.doi.org/10.11144/Javeriana.vj132.laic.

Lina Muñoz y Gloria A. Rodríguez, La participación en la gestión ambiental. Un reto para el nuevo milenio (Universidad del Rosario, 2009).

Lina Muñoz, Derechos de acceso en asuntos ambientales en Colombia. Hacia el desarrollo de una actividad minera respetuosa del entorno y las comunidades (CEPAL, Agencia Alemana de Cooperación Internacional [GIZ], 2017).

Manuel Calvo García, Transformaciones del Estado y del derecho (Universidad Externado de Colombia, 2005).

Manuel Díez, Derecho administrativo, tomo II, 203 (Bibliográfica Omeba, 1965).

María V. Calle, Cuando limitar la autonomía es maximizarla: derecho al medio ambiente sano como aporte a la optimización de la autonomía territorial 289, en G. Mendoza, J. Cepeda \& L. Estupiñán, eds., Una mirada a las regiones desde la justicia constitucional (Universidad del Rosario, Corte Constitucional de Colombia [C.C.], 2013).

Miguel Marienhoff, Tratado de derecho administrativo, tomo II, 218-220 (Abeledo-Perrot, 1988). 
OEA. Protocolo adicional a la Convención Americana sobre Derechos Humanos en materia de derechos económicos, sociales y culturales “Protocolo De San Salvador", 1988.

OEA. Carta Democrática Interamericana, 2001.

Oscar Amaya, Áreas protegidas en Colombia, definición, propiedad y bases constitucionales para su protección 23-59, en A. Embid \& M.P. García, eds., La conservación de la naturaleza, su régimen jurídico en Colombia y España (Universidad Externado de Colombia, 2018).

Oscar Amaya, La constitución ecológica de Colombia (3. ed., Universidad Externado de Colombia, 2016).

Pacto Internacional de Derechos Civiles y Políticos, 1966.

Pedro Aberastury \& Patricia Gottschau, Interrelación del derecho supranacional en el procedimiento administrativo nacional 80-117, en P. Aberastury \& H. Blanke, eds., Tendencias Actuales del Procedimiento Administrativo en Latinoanérica y Europa. Presentación de la traducción de la Ley alemana de procedimiento administrativo (Fundación Konrad Adenauer, Eudeba, 2011).

Rocío Araujo, El procedimiento administrativo colombiano como garantía de los derechos del ciudadano, en P. Aberastury \& H. Blanke, eds., Tendencias actuales del procedimiento administrativo en Latinoamérica y Europa. Presentación de la traducción de la Ley alemana de procedimiento administrativo 399-353 (Fundación Konrad Adenauer, Eudeba, 2011).

Santiago Muñoz, Las concepciones del derecho administrativo y la idea de participación en la administración, (84) Revista de Administración Pública 519-536 (1977), https://dialnet.unirioja.es/servlet/articulo?codigo=1098092

\section{Notas}

* Artículo de investigación científica. Resultado de la investigación "La repercusión del principio de participación en la teoría del acto administrativo: un análisis de su incidencia en el carácter unilateral de los actos administrativos en el marco de los procedimientos administrativos para la expedición de licencias ambientales y de la negociación colectiva de los empleados públicos".

1 E. Schmidt-Assmann, La teoría general del derecho administrativo como sistema. Objeto y fundamentos de la construcción sistemática (Marcial Pons, Ediciones Jurídicas y Sociales, 2003).

2 D. C. Sánchez Zapata \& H. D. Vergara Mesa, Procedimiento administrativo y posacuerdo: el principio de participación en la formación de las decisiones administrativas, 17 (35) Opinión Jurídica 185-208 (2018), https://doi.org/10.22395/oj um.v17n35a8

3 E. Schmidt-Assmann, supra nota 1, pág. 128.

4 Por su origen interdisciplinario el medio ambiente debe ser interpretado con apoyo en otras disciplinas. En este artículo se alude a la protección ambiental de manera genérica, tal y como se expresa en los términos constitucionales que aluden indistintamente a los conceptos de ambiente, medio ambiente sano, medio ambiente y recursos naturales. Véase O. Amaya Navas, La constitución ecológica de Colombia (3. a ed., Universidad Externado de Colombia, 2016).

$5 \quad$ En la Ley 1955 de 2019. Por el cual se expide el Plan Nacional de Desarrollo 2018-2022, se destacan el "Pacto por la sostenibilidad: producir conservando y conservar produciendo" y el "Pacto por los recursos minero-energéticos para el crecimiento sostenible y la expansión de oportunidades".

6 C. Courtis, El juego de los juristas. Ensayo de caracterización de la investigación dogmática, 106, en C. Courtis y A. Manuel, eds., Observar la ley\#: ensayos sobre metodología de la investigación jurídica 183-122 (Ed. Trotta, 2006).

7 E. Schmidt-Assmann, El concepto de la constitucionalización del derecho administrativo 33, en A. Montaña \& A. Ospina, eds., La constitucionalización del derecho administrativo. XV Jornadas Internacionales de Derecho Administrativo 21-38 (Universidad Externado de Colombia, 2014).

8 E. Schmidt-Assmann, La teoría general del derecho administrativo como sistema. Objeto y fundamentos de la construcción sistemática (Marcial Pons, Ed. Jurídicas y Sociales, 2003).

9 A. Montaña \& A. Ospina, eds., La constitucionalización del derecho administrativo (Universidad Externado de Colombia, 2014).

10 Id.

11 S. Muñoz, Las concepciones del derecho administrativo y la idea de participación en la administración, 84 Revista de administración pública 532, 519-536 (1977), https://dialnet.unirioja.es/servlet/articulo?codigo=1098092

12 Véase al respecto C. Moreno, Derecho administrativo y neoliberalismo: narrativa de una relación, en Nuevas tendencias del derecho administrativo 101-119 (H. Alviar, coord., Universidad de los Andes, Temis, 2016). La pandemia por la 
covid-19 ha mostrado una faceta diferente del Estado en la que retoma en parte su rol de gestor social, sin que sea posible vislumbrar desde ahora si esta misma faceta se mantendrá en el tiempo.

13 F. Marín, Público privado. Estudio sobre las transformaciones del derecho, del Estado y de la empresa (Temis, 2008).

14 A. Hernández, Administración pública, derecho administrativo y constitución 43, en H. Arenas, Instituciones de derecho administrativo, tomo I (Ibáñez, Universidad del Rosario, 2016).

15 M. Calvo García, Transformaciones del Estado y del derecho (Universidad Externado de Colombia, 2005).

16 H. Santaella, Del principio de legalidad al principio de juridicidad: implicaciones para la potestad normativa de la administración de una transición constitucionalmente impuesta 79-115, en A. Montaña \& A, Ospina, eds., La constitucionalización del derecho administrativo. XV Jornadas Internacionales de Derecho Administrativo (Universidad Externado de Colombia, 2014).

17 Id, pág. 99.

18 E. García de Enterría. Democracia, jueces y control de la administración 130-131 (4.a ed., Civitas, 2004).

19 J. O. Santofimio, Compendio de derecho administrativo 90 (Universidad Externado de Colombia, 2017).

20 Como lo muestra J.Æt. Meilán, Maurice Hauriou en perspectiva 27-58, en A. Matilla, J.\#. Santofimio \& H. Santaella, Ensayos de derecho público. En memoria de Maurice Hauriou (Universidad Externado de Colombia, 2013).

21 E. García de Enterría \& T. R. Fernández. Curso de derecho administrativo, vol. 1 (Civitas, 1993).

22 Id, pág. 469.

23 J.L. Meilán, Maurice Hauriou en perspectiva 42, en A. Matilla, J.O. Santofimio \& H. Santaella, Ensayos de derecho público. En memoria de Maurice Hauriou (Universidad Externado de Colombia, 2013).

24 E. Schmidt-Assmann, supra nota 1, pág. 99.

25 A. Hernández, supra nota 14, pág. 46.

26 H. Marín, El procedimiento administrativo como herramienta para la paz, en A. Montaña \& A. Ospina, eds., La constitucionalización del derecho administrativo (Universidad Externado de Colombia, 2014).

27 E. Schmidt-Assmann, supra nota 1, pág. 119.

28 J. Barnes, Tres generaciones de procedimiento administrativo, en P. Aberastury \& H. Blanke, eds. Tendencias actuales del procedimiento administrativo en Latinoamérica y Europa. Presentación de la traducción de la Ley alemana de procedimiento administrativo 120-164 (Fundación Konrad Adenauer, Eudeba, 2011).

29 Id, págs. 122-124.

30 Santofimio se refiere a la influencia austriaca que posteriormente se evidencia en el derecho administrativo francés. Véase J.\#. Santofimio, Fundamentos de los procedimientos administrativos en el Código de Procedimientos Administrativo y de lo Contencioso Administrativo - Ley 1437 de 2011-, 145-186, en Memorias Seminario Internacional de presentación del Nuevo Código de Procedimiento Administrativo y de lo Contencioso Administrativo. Ley 1437 de 2011 (Imprenta Nacional de Colombia, 2012).

31 R. Araujo, El procedimiento administrativo colombiano como garantía de los derechos del ciudadano 402, en P. Aberastury \& H. Blanke, eds., Tendencias actuales del procedimiento administrativo en Latinoamérica y Europa. Presentación de la traducción de la Ley alemana de procedimiento administrativo 399-353 (Fundación Konrad Adenauer, Eudeba, 2011).

32 E. Castro, Derecho ambiental y gobernanza 25 (Universidad de Medellín, 2017).

33 A. F. Ospina, La eficacia en el derecho administrativo colombiano: de advenediza a reina. Reflexiones a partir de la obra de Eberhard Schmidt-Assmann, en J. O. Santofimio, J. Barnés \& M. L. Ibagón, eds., Perspectivas de una reforma. Estudios de derecho administrativo a partir de la obra de Eberhard Schmidt-Assmann (Universidad Externado de Colombia, 2016).

34 J. Barnés, Buena administración, principio democrático y procedimiento administrativ., 21 Revista Digital de Derecho Administrativo 77-123 (2019).

35 E. Schmidt-Assmann, supra nota 1, pág. 119.

36 A. F. Ospina, supra nota 33.

37 E. Schmidt-Assmann, supra nota 1, págs. 12-15.

38 J. Barnés, Buena Administración, principio democrático y procedimiento administrativ., 21 Revista Digital de Derecho Administrativo 104 (2019).

39 P. Aberastury \& P. Gottschau, Interrelación del derecho supranacional en el procedimiento administrativo nacional 80-117, en P. Aberastury H. \& Blanke, eds., Tendencias Actuales del Procedimiento Administrativo en Latinoamérica y Europa. Presentación de la traducción de la Ley alemana de procedimiento administrativo (Fundación Konrad Adenauer, Eudeba, 2011).

40 Véase O. Amaya, Areas protegidas en Colombia, definición, propiedad y bases constitucionales para su protección 23-59, en A. Embid, M. P. García, eds., La conservación de la naturaleza, su régimen jurídico en Colombia y España (Universidad Externado de Colombia, 2018). M. Briceño, Responsabilidad y protección del ambiente: la obligación positiva del Estado (Universidad Externado de Colombia, 2017), y G. Ortega, Constitucionalismo ambiental y derechos ambientales: análisis de la evolución del Estado ambiental de derecho, el ambientalismo y la formación del precedente judicial ambiental 43-123, 
en G. Mesa, Derechos ambientales en disputa: algunos estudios de caso sobre conflictividad ambiental (Universidad Nacional de Colombia, 2015).

41 M. V. Calle, Cuando limitar la autonomía es maximizarla: Derecho al medio ambiente sano como aporte a la optimización de la autonomía territorial 289, en G. Mendoza, J. Cepeda, y L. Estupiñán, eds., Una mirada a las regiones desde la justicia constitucional (Universidad del Rosario, Corte Constitucional [C.C.], Colom., 2013).

42 Previstos en la Ley 99 de 1993. Por la cual se crea el Ministerio del Medio Ambiente, se reordena el Sector Público encargado de la gestión y conservación del medio ambiente y los recursos naturales renovables, se organiza el Sistema Nacional Ambiental, SINA y se dictan otras disposiciones, Colom.

43 Ley 1437 de 2011. Por la cual se expide el Código de Procedimiento Administrativo y de lo Contencioso Administrativo. En el CPACA se presenta el principio de participación a través de distintas reglas del procedimiento, arts. 6, 13-33, 37, 38,46 y 65 y ss., Colom.

44 P. Aberastury \& H. Blanke, eds., Tendencias Actuales del Procedimiento Administrativo en Latinoamérica y Europa. Presentación de la traducción de la Ley alemana de procedimiento administrativo (Fundación Konrad Adenauer, Eudeba, 2011).

45 C.P., arts. $1^{\circ}, 3,2940,79,103$, Colom.

46 Decreto 1076 de 2015. Por medio del cual se expide el Decreto Único Reglamentario del Sector Ambiente y Desarrollo Sostenible, art. 2.2.2.3.1.3, Colom.

47 La reglamentación de las licencias ambientales ha sido objeto de múltiples modificaciones como lo muestran Juliette Sleman-Chams \& Carlos Javier Velásquez-Muñoz, La licencia ambiental: ¿instrumento de comando y control por excepción?, 132 Vniversitas 483-514 (2016), http://dx.doi.org/10.11144/Javeriana.vj132.laic.

48 De acuerdo con el artículo 42 de la Ley 685 de 2001.

49 En el Atlas de Justicia Ambiental, Colombia es catalogado como el país con mayor cantidad de conflictos socioambientales de Latinoamérica, que se caracterizan por las demandas de participación de las comunidades afectadas por proyectos mineros o extractivos que se consideran insatisfechas por la Administración o por las autoridades competentes. http://www.ejolt.org/project/ [consultado: 4 de mayo de 2020].

50 Principio 10 de la Declaración de Río: "El mejor modo de tratar las cuestiones ambientales es con la participación de todos los ciudadanos interesados, en el nivel que corresponda".

51 Cabe mencionar, por ejemplo, algunos instrumentos para definir el alcance del derecho fundamental de la participación: artículo 11 del Protocolo de San Salvador; en el artículo $4^{\circ}$ de la Convención Marco de las Naciones Unidas sobre el Cambio Climático; y en los artículos 14.1 a) del Convenio sobre la Diversidad Biológica y la Declaración de Río de Janeiro de 1992.

52 Es el caso del Acuerdo Regional sobre el Acceso a la Información, la Participación Pública y el Acceso a la Justicia en Asuntos Ambientales en América Latina y el Caribe (Acuerdo de Escazú), que desarrolla el principio 10 de la Declaración de Río, https://observatoriop10.cepal.org/es/tratados/acuerdo-regional-acceso-la-informacion-la-participacion-public a-acceso-la-justicia-asuntos. El Gobierno colombiano anunció a finales de 2019 que ratificaría dicho acuerdo.

53 Criterios compilados por la Corte Constitucional de Colombia [C.C.], Sentencia T-361 de 2017, M.P.: A. Rojas Ríos. Véase también: [C.C.], sentencias T-348 de 2012, T-294 de 2014 y T-660 de 2015. A su vez, esta corporación precisó la relevancia que tiene el derecho al acceso de la información, y la intervención real y efectiva de las personas en los trámites decisorios para la garantía de la participación.

54 En la Opinión Consultiva OC-23/17 del 15 de noviembre de 2017, se reconoció el carácter del derecho al ambiente sano como un derecho humano autónomo que puede ser protegido directamente por el artículo 26 de la Convención Americana de Derechos Humanos, http://www.corteidh.or.cr/docs/opiniones/seriea_23_esp.pdf.

55 L. Muñoz Ávila \& G. A. Rodríguez, La participación en la gestión ambiental. Un reto para el nuevo milenio (Universidad del Rosario, 2009). L. Muñoz Ávila, Derechos de acceso en asuntos ambientales en Colombia. Hacia el desarrollo de una actividad minera respetuosa del entorno y las comunidades (CEPAL, Agencia Alemana de Cooperación Internacional [GIZ], 2017).

56 Contraloría General de la República, El proceso administrativo de licenciamiento ambiental en Colombia (2017). G. Rodríguez, Problemáticas y elementos asociados al proceso administrativo para el otorgamiento de licencias en Colombia 357-385, en M. Restrepo, ed., Derecho administrativo. Reflexiones contemporáneas (2017).

57 Autores como Marienhoff han atribuido una relevancia trascendental al acto administrativo y a la teoría que se ocupa de su estudio, ya que "gran parte de las de las vinculaciones de la Administración pública con los administrados o particulares, tiene por base a un acto administrativo", y a que es la forma por excelencia en que la Administración expresa su voluntad. M. Marienhoff, Tratado de derecho administrativo, tomo II, 218-220 (Abeledo-Perrot, 1988).

58 A. Gómez, G. Rodríguez \& I. Vargas. De la nulidad y el restablecimiento del derecho: La complejidad que supone el éxito de los medios de control sobre los actos administrativos relacionados con la licencia ambiental, 223-247, en G. Rodríguez, ed., Justicia ambiental en Colombia: ejercicio participativo a través de las acciones constitucionales 14 (Ibáñez, 2018).

59 M. Díez, Derecho administrativo, tomo II, 203 (Bibliográfica Omeba, 1965). 
60 E. Sayagués Lasso, Tratado de derecho administrativo, tomo I, 382 y 389 (6. ed., Fundación de Cultura Universitaria, 1988).

61 Id.

62 J. O. Santofimio, Tratado de derecho administrativo, acto administrativo, procedimiento, eficacia y validez 355 (4.a ed., Universidad Externado de Colombia, 2003).

63 Decreto 1076 de 2015, art. 2.2.2.3.1.2, Colom.

64 Corte Constitucional de Colombia [C.C.], Sentencias T-294 de 2014, M.P.: M. V. Calle Correa T-660 de 2015, M.P.: J. I. Pretelt y T-599 de 2016, M.P.: L. E. Vargas y T-348 de 2012, M.P.: J. I. Pretelt [Colom.].

65 Ley 1437 de 2011 , num. 6 , art. $2^{\circ}$, num. 8 , art. $5^{\circ}$, arts. 34 y 35 , Colom.

66 El reconocimiento del principio de participación se extiende a diferentes instrumentos que integran el bloque de constitucionalidad: Declaración Universal de los Derechos Humanos, 1948, art. 21; Pacto Internacional de Derechos Civiles y Políticos, 1966, art. 25; Declaración Americana de los Derechos y Deberes del Hombre, 1948, arts. 13, 20, 21 y 22; Convención Americana sobre Derechos Humanos, 1969, art. 23; Carta Democrática Interamericana, 2001, art. 6. En materia ambiental tiene una consagración especial en el Principio 10 de la Declaración de Río de Janeiro.

67 En la Sentencia T-361 de 2017, la Corte Constitucional de Colombia, a propósito del estudio del caso concreto en el que debía decidir si la actividad del Ministerio de Ambiente y Desarrollo Sostenible, al expedir un acto administrativo, había desconocido el principio de participación de las comunidades, retomó las reglas constitucionales relativas a los alcances y proyección constitucional de la participación, desde la perspectiva de la justicia ambiental.

68 E. Schmidt-Assmann, supra nota 1, págs. 318, 319.

69 Decreto 1076 de 2015, art. 2.2.2.3.6.6., Colom.

70 Corte Constitucional de Colombia [C.C.], Sentencia T-348 de 2012, M.P.: J. I. Pretelt y Sentencia T-294 de 2014, M.P.: M. V. Calle [Colom.].

71 G. Rodríguez, Autorizaciones y procesos administrativos y ambientales 415-454, en H. Arenas, Instituciones de derecho administrativo. Tomo I. La administración y su actividad (Universidad del Rosario, Ibáñez, 2016).

72 J. O. Santofimio, Compendio de derecho administrativo 90 (Universidad Externado de Colombia, 2017).

73 G. Rodríguez, supra nota 71.

74 Corte Constitucional de Colombia [C.C.], Sentencia C-894 de 2003, M.P.: R. Escobar [Colom.].

\section{Licencia Creative Commons CC BY 4.0}

Cómo citar este artículo: Diana Carolina Sánchez-Zapata \& Hernán Darío Vergara-Mesa, La incidencia del principio de participación ambiental en la teoría del acto administrativo, 70 Vniversitas (2021), https://doi.o $\mathrm{rg} / 10.11144 /$ Javeriana.vj70.ippa 